\title{
Characterization of clinical, laboratory, IL-6 serum levels, and IL-6-174 G/C genetic polymorphisms in patients with rheumatoid arthritis and Sjögren's syndrome
}

\author{
Thayanara Silva Melo* (1), Marília Lins e Silva (1), Mário Luciano de Mélo Silva Júnior² (1), \\ Angela Pinto Duarte ${ }^{3}$, Luiz Alcino Gueiros ${ }^{1}$
}

\begin{abstract}
SUMMARY
OBJECTIVE: This study aimed to characterize the clinical (disease activity and exocrine gland function), laboratory, interleukin 6 (IL-6) serum levels, and IL-6-174G/C (rs1800795) genetic polymorphisms among rheumatoid arthritis (RA), RA plus Sjögren's syndrome (RA+SS), and control subjects. METHODS: A case-control study enrolling 137 women ( $52 \pm 11$ years old) were divided into three groups as follows: RA ( $n=70), R A+S S$ $(n=29)$, and healthy control $(C, n=38)$. Individuals underwent clinical evaluation composed of Schirmer's test, unstimulated salivary flow rate, and evaluation of disease activity and functional capacity (Disease Activity Score [DAS28] and Health Assessment Questionnaire [HAQ]). IL-6 serum levels and IL-6-174G/C polymorphisms were assessed.

RESULTS: RA and RA+SS presented higher serum levels of IL- 6 than controls $(p<0.001)$. Also, higher IL- 6 levels were related to swollen joints ( $p=0.038$ ), limited functional capacity $(p=0.004)$, and disease activity $(p \leq 0.001)$. However, neither IL-6-174G/C genetic polymorphism nor its allele frequency was associated with RA or RA+SS.

CONCLUSION: IL-6 serum is an important marker of RA activity and functional incapacity, but IL-6-174G/C genetic polymorphism did not differ among healthy controls and cases.

KEYWORDS: Sjögren's syndrome. Rheumatoid arthritis. Genetic polymorphism. IL-6.
\end{abstract}

\section{INTRODUCTION}

Interleukin 6 (IL-6) is a pro-inflammatory cytokine related to the pathogenesis and perpetuation of both rheumatoid arthritis (RA) and Sjögren's syndrome (SS) ${ }^{1}$, as well as of other autoimmune diseases.

Although high IL-6 rates have been observed in patients with RA and considered to be largely genetically determined ${ }^{2,3}$. Studies indicate that single nucleotide polymorphism, such as $-174 \mathrm{G} / \mathrm{C}$ (rs1800795) of the IL-6 gene promoter region, plays a role in influencing IL- 6 protein transcription and serum levels ${ }^{4}$.
In tandem with it, there is a positive correlation between IL-6 serum levels and RA activity ${ }^{5}$.

Although studies suggest the involvement of IL-6 in disease progression, the predominant genetic profile in RA needs to be better understood, thus providing insights for the development of future patient management strategies. Therefore, this study aimed to assess the serological levels of IL- 6 and the genetic polymorphism of IL-6-174G/C in patients with RA and RA+SS, as well as to correlate them with clinical, ophthalmological, and oral evaluation.

\footnotetext{
'Universidade Federal de Pernambuco, Unidade de Medicina Oral, Departamento de Clínica e Odontologia Preventiva - Recife (PE), Brazil.

${ }^{2}$ Centro Universitário Maurício de Nassau, Escola de Medicina - Recife (PE), Brazil.

${ }^{3}$ Universidade Federal de Pernambuco, Hospital das Clínicas, Unidade de Reumatologia - Recife (PE), Brazil.

*Corresponding author: thayanara.melo@ufpe.br

Conflicts of interest: the authors declare there is no conflicts of interest. Funding: none.

Received on July 14, 2021. Accepted on August 24, 2021.
} 


\section{METHODS}

\section{Study design and sample characteristics}

Cross-sectional control-matched study enrolling women who are 18 years or older, in a convenience sample. RA, RA+SS, and SS volunteers were invited in a tertiary center (Rheumatology Unit of Hospital das Clínicas, Universidade Federal de Pernambuco). Controls were invited to the Stomatology Unit of the same university and matched for age with individuals with RA.

All individuals were assessed for sicca syndrome and classified as SS according to the criteria of the AmericanEuropean College of Consensus ${ }^{6}$. The diagnosis of RA was based on the criteria determined by the American College of Rheumatology ${ }^{7}$.

Exclusion criteria were the history of radiotherapy in the head and neck, HIV or HCV infection, sarcoidosis, amyloidosis, graft versus host disease, and using anticholinergic drugs. The approval by the ethical review board was obtained, and all individuals agreed voluntarily to participate.

\section{Assessment of disease activity}

The Disease Activity Score 28 (DAS28) was applied. It assesses 28 joints for pain and swell, rate of erythrocyte sedimentation or C-reactive protein as an inflammatory marker, and a scale of self-perception of disease activity from 0 to 100 .

\section{Clinical evaluations}

Functional capacity was determined using the Portuguese version of the Health Assessment Questionnaire (HAQ). This instrument assesses the functional status of patients with RA. For each of the eight categories, the patient indicated the degree of difficulty to perform daily activities in four possible responses ranging from "no difficulty $=0$ " to "unable to do it $=3$."

Visual analog scales (VAS), ranging from 0 to 100 , were also used to assess the self-perception of general condition (VAS of general condition affliction) and fatigue in the previous week reported by the patient.

\section{Evaluation of xerostomia}

We applied the Portuguese version of the Xerostomia Inventory. This inventory consists of 11 questions with a 5-item Likert scale for each item. The sum ranges from 11 to 55, and higher values correspond to a more pronounced perception of xerostomia.

\section{Resting salivary flow (RSF) collection}

Saliva to evaluate resting salivary flow (RSF) was collected by obtaining whole non-stimulated saliva. Collection occurred by the spitting method, lasting $15 \mathrm{~min}$ and administered in the morning.

\section{Evaluation of IL-6 concentration in serum}

IL-6 was measured from serum samples. The human Cytometric Bead Array (CBA) Kit Th1/Th2/Th17 (BD ${ }^{\mathrm{TM}}$ Cytometric Bead Array (CBA), Catalog \#560484, BD Bioscience, San Jose, CA, USA) was used according to the manufacturer's recommendations. The IL-6 detection limit is $2.4 \mathrm{pg} / \mathrm{mL}$. Data acquisition was performed using the FACSCalibur cytometer (BD Bioscience), and the analyzes were performed using FCAP Array v3.0 software (Soft Flow Inc.).

\section{DNA extraction and detection of the polymorphic variant}

The DNA of the samples was isolated from whole blood (EDTA) with the QIAamp Mini Spin Columns DNA Kit (QIAGEN) following the manufacturer's instructions. The samples were genotyped for IL-6-174G/C (rs1800795) using a TaqMan assay (Applied Biosystems, Foster City, CA, USA). Allele-specific probes were labeled with the fluorescent dyes VIC and FAM, respectively.

\section{Statistical analysis}

The data are presented according to the following three groups based on the clinical evaluation: RA, RA+SS, and control. Data are expressed in mean \pm standard deviation. Quantitative variables were assessed in groups with Kruskal-Wallis or ANOVA, according to the normality distribution by the D'Agostino and Pearson's test. Binary categorical variables were analyzed using the Fisher's test; the chi-square test was used for categorical non-binary variables. Spearman's correlation was applied for the analysis of two quantitative variables.

The data were analyzed using the GraphPad Prism software version 6.0 for Windows. An alpha coefficient of 5\% was adopted.

\section{RESULTS}

\section{Sample characteristics}

Our sample is composed of 70 women with RA, 29 with RA+SS, and 38 controls. Table 1 describes sample characteristics.

\section{Oral assessment}

Xerostomia was reported for 28/29 (97\%) in individuals with RA+SS and for 27/70 (39\%) in individuals with RA $(\mathrm{p}<0.001)$ and controls 5/38 (13\%). Reduced resting salivary flow rate was more frequent in the SS+RA group (26/29, $90 \%)$ compared with RA $(5 / 70,7 \%)$ and controls $(6 / 38$, $16 \%)(\mathrm{p}<0.001)$. The mean RSF was significantly lower in the $\mathrm{RA}+\mathrm{SS}$ group (Table 1 ). 
Table 1. Sample characterization.

\begin{tabular}{|c|c|c|c|c|}
\hline \multirow{2}{*}{ Characteristics } & \multicolumn{3}{|c|}{ Group } & \multirow{2}{*}{$p$} \\
\hline & Control $(n=38)$ & $R A+S S(n=29)$ & $\mathrm{RA}(\mathrm{n}=70)$ & \\
\hline Age & $52.3 \pm 12.2$ & $53.6 \pm 9.1$ & $50.9 \pm 11.4$ & 0.736 \\
\hline RSF positive & $6(16)$ & $26(90)$ & $5(7)$ & $<0.001 *$ \\
\hline RSF & $0.3 \pm 0.3$ & $0.06 \pm 0.08$ & $0.4 \pm 0.3$ & $<0.001 *$ \\
\hline ESR & $19.9 \pm 14.9$ & $37.4 \pm 25.5$ & $35.0 \pm 25.3$ & $0.004^{*}$ \\
\hline Schirmer & $12.5 \pm 11.1$ & $2.1 \pm 1.8$ & $10.4 \pm 9.8$ & $<0.001 *$ \\
\hline Schirmer positive & $7(19)$ & $29(100)$ & $21(27)$ & $<0.001 *$ \\
\hline Xerophthalmia & $4(11)$ & $21(72)$ & $29(41)$ & $<0.001 *$ \\
\hline Xerostomia & $5(13)$ & $28(97)$ & $27(39)$ & $<0.001 *$ \\
\hline Xerostomia inventory & $17.4 \pm 7.1$ & $31.6 \pm 11.1$ & $21.3 \pm 9.3$ & $<0.001 *$ \\
\hline DAS28 & - & $4.6 \pm 1.8$ & $4.4 \pm 1.6$ & 0.539 \\
\hline $\mathrm{DAS}^{\circ} 8^{+}$ & - & $22(79)$ & $51(74)$ & 0.796 \\
\hline HAQ & - & $1.3 \pm 0.9$ & $1.3 \pm 0.9$ & 0.814 \\
\hline $\mathrm{HAQ}$ & - & $16(57)$ & $38(56)$ & 1.000 \\
\hline EVA & - & $56.1 \pm 28.5$ & $53.9 \pm 32.9$ & 0.921 \\
\hline Fatigue & - & $55.0 \pm 36.6$ & $53.8 \pm 35.4$ & 0.802 \\
\hline Disease time & - & $10.9 \pm 9.3$ & $9.1 \pm 6.8$ & 0.540 \\
\hline Joint pain ${ }^{\ddagger}$ & - & $7.0 \pm 8.9$ & $7.1 \pm 9.9$ & 0.876 \\
\hline Swollen join ${ }^{\ddagger}$ & - & $3.4 \pm 4.0$ & $2.3 \pm 4.1$ & $0.048 *$ \\
\hline
\end{tabular}

Data expressed as mean \pm SD and $n$ (\%). RA: rheumatoid arthritis; SS: Sjögren's syndrome; RSF: resting salivary flow; ESR: erythrocyte sedimentation rate; DAS28 = Disease Activity Score 28; HAQ: Health Assesment Questionnaire. *Statistical significance; age and time of illness in years; ${ }^{\dagger}$ Moderate and severe strata; Number of joints.

\section{Ophthalmological evaluation}

Xerophthalmia was reported by $4 / 38$ (11\%) controls, 29/70 (41\%) patients with RA, and 21/29 (72\%) individuals with $R A+S S(p<0.001)$. All individuals in the RA+SS group showed an aqueous deficiency $(29 / 29)$ on the Schirmer's test, while it was observed on $21 / 70$ (27\%) in the RA group and 7/38 (19\%) among controls $(\mathrm{p}<0.001)$ (Table 1).

\section{Disease activity and functional capacity assessment}

The mean DAS28 score was similar in the RA+SS and RA groups ( $4.6 \pm 1.8$ vs. $4.4 \pm 1.6, p=0.539$ ). For functional capacity, there was also no significant difference between them.

\section{Joint edema}

The number of swollen joints was significantly higher in the

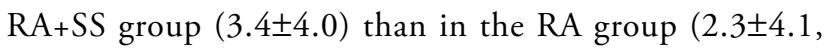
$\mathrm{p}=0.048)$. There was no difference in the number of painful joints between them (Table 1).
Correlation of IL- 6 serum levels and clinical and laboratory variables in RA and RA+SS groups

In RA and RA+SS groups, IL-6 levels positively correlate with erythrocyte sedimentation rate (ESR), DAS28, HAQ, and joint pain $(\mathrm{r}=0.421, \mathrm{p}<0.001 ; \mathrm{r}=0.334, \mathrm{p}<0.001 ; \mathrm{r}=0.292, \mathrm{p}=0.004$; $\mathrm{r}=0.209, \mathrm{p}=0.038$, respectively).

\section{Association of IL-6 with}

polymorphism and allele frequencies

Allele frequencies did not differ significantly between the RA+SS, $\mathrm{RA}$, and $\mathrm{C}$ groups (Table 2). The genotype distributions are shown in Table 3. Patients in the RA group (GG 53.5\%, GC $62.5 \%$, and CC $66.6 \%$ ) and the RA+SS group (GG 21.1\%, CG $15.6 \%$, and CC $0 \%$ ) had no significant difference from controls (GG 25.3\%, CG 21.8\%, and CC 33.3\%) ( $\mathrm{p}=0.691$ ).

\section{IL-6 levels by clinical groups}

IL-6 serum levels were significantly higher in the RA and RA+SS groups when compared with the $C$ individuals ( $R A=10.8 \pm 33.4$, $\mathrm{RA}+\mathrm{SS}=6.5 \pm 8.2$, and $\mathrm{C}=0.41 \pm 0.9 ; \mathrm{p}<0.001)$. Nevertheless, no difference was observed between RA and RA+SS groups $(\mathrm{p}=0.391)$. 
Table 2. Allele frequency of interleukin-6 174G/C in all clinical groups.

\begin{tabular}{|c|c|c|c|c|c|c|}
\hline \multirow{3}{*}{ Group } & \multicolumn{4}{|c|}{ Allele } & \multirow{3}{*}{$p$} & \multirow{3}{*}{$95 \% \mathrm{Cl}$} \\
\hline & \multicolumn{2}{|c|}{$C$} & \multicolumn{2}{|c|}{ G } & & \\
\hline & $n$ & $\%$ & $n$ & $\%$ & & \\
\hline Case & 33 & 75 & 82 & 66 & \multirow{2}{*}{0.276} & \multirow{2}{*}{$\begin{array}{c}0.72- \\
3.42\end{array}$} \\
\hline Control & 11 & 25 & 43 & 44 & & \\
\hline $\mathrm{RA}+\mathrm{SS}$ & 5 & 31 & 35 & 44 & \multirow{2}{*}{0.410} & \multirow{2}{*}{$\begin{array}{c}0.18- \\
1.80\end{array}$} \\
\hline Control & 11 & 69 & 43 & 46 & & \\
\hline RA & 27 & 71 & 96 & 69 & \multirow{2}{*}{1.000} & \multirow{2}{*}{$\begin{array}{c}0.50- \\
2.42\end{array}$} \\
\hline Control & 11 & 19 & 43 & 31 & & \\
\hline $\mathrm{RA}+\mathrm{SS}$ & 5 & 15 & 35 & 27 & \multirow{2}{*}{0.254} & \multirow{2}{*}{$\begin{array}{c}0.18- \\
1.42\end{array}$} \\
\hline RA & 27 & 85 & 96 & 73 & & \\
\hline
\end{tabular}

Case: rheumatoid arthritis and rheumatoid arthritis+secondary Sjögren's syndrome; RA: rheumatoid arthritis; SS: secondary Sjögren's syndrome.

Table 3. Interleukin-6 174G/C genotype per groups.

\begin{tabular}{l|c|c|c|c|c|c|c|}
\multirow{2}{*}{ Genotype } & \multicolumn{6}{|c|}{ Clinical profile } & \multirow{2}{*}{ p } \\
\cline { 2 - 7 } & \multicolumn{2}{|c|}{ Control } & \multicolumn{2}{|c|}{ RA+SS } & \multicolumn{2}{|c|}{ RA } & \\
\cline { 2 - 7 } & $\mathrm{n}$ & $\%$ & $\mathrm{n}$ & $\%$ & $\mathrm{n}$ & $\%$ & \\
\hline CC & 2 & 7.4 & 0 & 0.0 & 4 & 6.4 & \\
\hline GC & 7 & 25.9 & 5 & 25.0 & 20 & 32.3 & \multirow{2}{*}{0.691} \\
\hline GG & 18 & 66.7 & 15 & 75.0 & 38 & 61.3 & \\
\hline Total & 27 & 100 & 20 & 100 & 62 & 100 & - \\
\hline
\end{tabular}

RA: rheumatoid arthritis; SS: secondary Sjögren's syndrome.

\section{DISCUSSION}

We found that IL-6 serum levels correlated with RA activity and ERS, but we found no association between allelic frequency of IL-6-174G/C polymorphism and clinical phenotypes.

IL-6 is a cytokine produced by lymphocytes, monocytes, and fibroblasts, which plays a key role in the maturation of B cells and the production of autoantibodies ${ }^{8}$. IL- 6 acts as a pro-inflammatory mediator in the face of inflammatory stimuli ${ }^{9,10}$. During the acute inflammation phase of RA, serum IL-6 levels can be used as a biomarker of inflammation or disease activity ${ }^{9}$, in line with our finding that the higher levels of IL-6 in patients with higher DAS28 scores. Several lines of studies have pointed that individuals with elevated IL-6 serum levels are likely to present higher levels of those in the synovial fluid, and these findings are associated with disease activity and joint destruction ${ }^{11,12}$. HAQ is a measure that evaluates the functional disability reported by the patient, it also had a significant association with the serum level of IL-6.

In individuals with RA, the coexistence of SS has been associated with more severe diseases and worse prognoses ${ }^{13,14}$. We observed a higher number of swollen joints in the RA+SS group. SS is a chronic systemic inflammatory disorder that mainly affects exocrine glands, leading to xerostomia and xerophthalmia. It is characterized by the infiltration of mononuclear cells in the exocrine glands as well as acinar and ductal destruction, with consequent glandular hypofunction ${ }^{15}$. Salivary and lacrimal glands are the target organs for autoimmune attack mediated mainly by T cells. CD 4 cells in SS ${ }^{16}$ and IL- 6 are capable of stimulating numerous biological processes including $\mathrm{T}$ cell activation, $\mathrm{B}$ cell differentiation, and autoantibody production.

The GG genotype has already been associated with an increase in the production of this cytokine that is possibly related to the lymphocytic infiltration in the glandular stroma REF. This infiltration can lead to acinar and ductal destruction of epithelial cells and loss of the glandular parenchyma resulting in clinical signs and classic symptoms of dry mouth and eyes ${ }^{17}$. Although the presence of xerostomia and xerophthalmia has been associated with the diagnosis of SS, these clinical findings correlated neither with the serum levels nor with the genetic polymorphism of IL- 6 in this study.

Regarding the allelic and genotypic frequencies of the IL-6-174G/C genetic polymorphism, they were not associated with the presence of RA or SS. Report from the British population comparing patients with RA and controls also did not observe differences among IL-6 levels and the same polymorphism ${ }^{18}$. In fact, a systematic review showed heterogeneity in the association of IL- 6 genotypes and between individuals with RA from Europe, Asia, and eastern China and suggests that this divergence can probably be explained by different antecedent genetic disorders or linkage imbalance $^{19}$. In fact, studies have already reported that one gene variant plays different roles in the risk of RA in different populations and regions ${ }^{20-22}$. These findings suggest complex interactions with environmental and probably other genetic factors leading to clinical phenotypes ${ }^{23,24}$, as well as the importance of establishing specific databases of populations and regions.

This study has limitations. This was an unicenter study, and we have a relatively small sample size; then, maybe our results could not be representative, and the possibility of type II error should be kept in mind. 


\section{CONCLUSIONS}

IL-6 polymorphisms and allele frequency were not associated with the diagnosis of RA or RA+SS, but IL-6 levels were correlated with clinical findings, such as ESR, DAS28, and HAQ. In this context, the use of IL-6 as a marker of clinical activity may be useful. More studies are needed to evaluate its impact on disease progression.

\section{AUTHORS" CONTRIBUTIONS}

TSM: Conceptualization, Data curation, Investigation, Methodology. MLS: Conceptualization, Data Curation, Investigation. MLMSJ: Conceptualization, Data Curation, Formal analysis. APD: Project administration, Validation, Visualization. LAG: Project administration, Supervision, Validation, Visualization.

\section{REFERENCES}

1. Assier E, Boissier MC, Dayer JM. Interleukin-6: from identification of the cytokine to development of targeted treatments. Joint Bone Spine. 2010;77(6):532-6. https://doi.org/10.1016/j.jbspin.2010.07.007

2. Madhok R, Crilly A, Watson J, Capell HA. Serum interleukin 6 levels in rheumatoid arthritis: correlations with clinical and laboratory indices of disease activity. Ann Rheum Dis. 1993;52(3):232-4. https://doi.org/10.1136/ard.52.3.232

3. Robak T, Gladalska A, Stepien H, Robak E. Serum levels of interleukin- 6 type cytokines and soluble interleukin- 6 receptor in patients with rheumatoid arthritis. Mediators Inflamm. 1998;7(5):347-53. https://doi.org/10.1080/09629359890875

4. Fernandes MTP, Fernandes KBP, Marquez AS, Cólus IMS, Souza MF, Santos JPM, et al. Association of interleukin- 6 gene polymorphism (rs1800796) with severity and functional status of osteoarthritis in elderly individuals. Cytokine. 2015;75(2):31620. https://doi.org/10.1016/j.cyto.2015.07.020

5. Wang J, Platt A, Upmanyu R, Germer S, Lei G, Rabe C, et al. IL-6 pathway-driven investigation of response to IL-6 receptor inhibition in rheumatoid arthritis. BMJ Open. 2013;3(8):e003199. https://doi.org/10.1136/bmjopen-2013-003199

6. Vitali C, Bombardieri S, Jonsson R, Moutsopoulos HM, Alexander EL, Carsons SE, et al. Classification criteria for Sjögren's syndrome: a revised version of the European criteria proposed by the American-European Consensus Group. Ann Rheum Dis. 2002;61(6):554-8. https://doi.org/10.1136/ard.61.6.554

7. Arnett FC, Edworthy SM, Bloch DA, McShane DJ, Fries JF, Cooper NS, et al. The American Rheumatism Association 1987 revised criteria for the classification of rheumatoid arthritis. Arthritis Rheum. 1988;31(3):315-24. https://doi.org/10.1002/art.1780310302

8. Fonseca JE, Santos MJ, Canhão H, Choy E. Interleukin-6 as a key player in systemic inflammation and joint destruction. Autoimmun Rev. 2009;8(7):538-42. https://doi.org/10.1016/J.autrev.2009.01.012

9. Barnes TC, Anderson ME, Moots RJ. The many faces of interleukin-6: the role of IL-6 in inflammation, vasculopathy, and fibrosis in systemic sclerosis. Int J Rheumatol. 2011;2011:721608. https://doi.org/10.1155/2011/721608

10. Kishimoto T. Interleukin-6: from basic science to medicine--40 years in immunology. Annu Rev Immunol. 2005;23:1-21. https://doi.org/10.1146/annurev.immunol.23.021704.115806

11. Hirano T, Matsuda T, Turner M, Miyasaka N, Buchan G, Tang B, et al. Excessive production of interleukin 6/B cell stimulatory factor-2 in rheumatoid arthritis. Eur $\mathrm{J}$ Immunol. 1988;18(11):1797-801. https://doi.org/10.1002/eji.1830181122

12. Patel AM, Moreland LW. Interleukin-6 inhibition for treatment of rheumatoid arthritis: a review of tocilizumab therapy. Drug Des Devel Ther. 2010;4:263-78. https://doi.org/10.2147/DDDT.S14099

13. Young A, Koduri G. Extra-articular manifestations and complications of rheumatoid arthritis. Best Pract Res Clin Rheumatol. 2007;21(5):907-27. https://doi.org/10.1016/j.berh.2007.05.007
14. Martens PB, Pillemer SR, Jacobsson LT, O'Fallon WM, Matteson EL. Survivorship in a population based cohort of patients with Sjögren's syndrome, 1976-1992. J Rheumatol. 1999;26(6):1296300. PMID: 10381046

15. Tzioufas AG, Tatouli IP, Moutsopoulos HM. Autoantibodies in Sjögren's syndrome: clinical presentation and regulatory mechanisms. Presse Med. 2012;41(9 Pt 2):e451-60. https:// doi.org/10.1016/j.lpm.2012.05.022

16. Dörner T, Lipsky PE. Abnormalities of B cell phenotype, immunoglobulin gene expression and the emergence of autoimmunity in Sjögren's syndrome. Arthritis Res. 2002;4(6):360-71. https://doi.org/10.1186/ar603

17. Hulkkonen J, Pertovaara M, Antonen J, Pasternack A, Hurme M. Elevated interleukin- 6 plasma levels are regulated by the promoter region polymorphism of the IL 6 gene in primary Sjögren's syndrome and correlate with the clinical manifestations of the disease. Rheumatology (Oxford). 2001;40(6):656-61. https://doi.org/10.1093/rheumatology/40.6.656

18. Panoulas VF, Stavropoulos-Kalinoglou A, Metsios GS, Smith JP, Milionis HJ, Douglas KMJ, et al. Association of interleukin-6 (IL-6)-174G/C gene polymorphism with cardiovascular disease in patients with rheumatoid arthritis: the role of obesity and smoking. Atherosclerosis. 2009;204(1):178-83. https://doi. org/10.1016/j.atherosclerosis.2008.08.036

19. Li B, Xiao Y, Xing D, Ma XL, Liu J. Circulating interleukin-6 and rheumatoid arthritis: a Mendelian randomization metaanalysis. Medicine (Baltimore). 2016;95(23):e3855. https:// doi.org/10.1097/MD.0000000000003855

20. Barrera P, Boerbooms AM, Janssen EM, Sauerwein RW, Gallati $\mathrm{H}$, Mulder J, et al. Circulating soluble tumor necrosis factor receptors, interleukin-2 receptors, tumor necrosis factor alpha, and interleukin- 6 levels in rheumatoid arthritis. Longitudinal evaluation during methotrexate and azathioprine therapy. Arthritis Rheum. 1993;36(8):1070-9. https://doi.org/10.1002/ art.1780360807

21. Song GG, Bae SC, Kim JH, Lee YH. Association between TNF- $\alpha$ promoter -308 A/G polymorphism and rheumatoid arthritis: a meta-analysis. Rheumatol Int. 2014;34(4):465-71. https:// doi.org/10.1007/s00296-013-2919-5

22. Cheng $P$, Zhang $Y$, Huang $H$, Zhang $W$, Yang $Q$, Guo $F$, et al. Association between CCR6 and rheumatoid arthritis: a metaanalysis. Int J Clin Exp Med. 2015;8(4):5388-96. PMID: 26131115

23. Orozco G, Rueda B, Martin J. Genetic basis of rheumatoid arthritis. Biomed Pharmacother. 2006;60(10):656-62. https:// doi.org/10.1016/j.biopha.2006.09.003

24. Gonzalez-Gay MA, Garcia-Porrua C, Hajeer AH. Influence of human leukocyte antigen-DRB1 on the susceptibility and severity of rheumatoid arthritis. Semin Arthritis Rheum. 2002;31(6):355-60. https://doi.org/10.1053/sarh.2002.32552 